Int. J. Electrochem. Sci., 13 (2018) 3185 - 3199

International Journal of

ELECTROCHEMICAL

SCIENCE

www.electrochemsci.org

\title{
Conductivity and Electrical Properties of Chitosan - Methylcellulose Blend Biopolymer Electrolyte Incorporated with Lithium Tetrafluoroborate
}

\author{
Yahya A.K. Salman ${ }^{1}$, Omed Gh. Abdullah ${ }^{2,3, *}$, Rawad R. Hanna ${ }^{1}$, Shujahadeen B. Aziz ${ }^{2,3}$ \\ ${ }^{1}$ Department of Physics, College of Science, University of Mosul, 41002, Mosul, Iraq. \\ ${ }^{2}$ Advanced Polymeric Materials Research Lab., Department of Physics, College of Science, \\ University of Sulaimani, 46001, Kurdistan Region, Iraq. \\ ${ }^{3}$ Komar Research Center, Komar University of Science and Technology, 46001, Sulaimani, Kurdistan \\ Region, Iraq. \\ *E-mail: omed.abdullah@ univsul.edu.iq
}

doi: $10.20964 / 2018.04 .25$

Received: 29 November 2017 / Accepted: 28 January 2018 / Published: 6 March 2018

This work focuses on the structural and electrical properties of solid biopolymer blend electrolytes based on chitosan and methylcellulose incorporated with lithium tetrafluoroborate $\left(\mathrm{LiBF}_{4}\right)$. The polymer electrolyte films were prepared by solution casting technique. The polymer blend comprised of $75 \mathrm{wt} . \%$ chitosan and $25 \mathrm{wt} \%$ methylcellulose, the most amorphous blend composition are used as the host matrix. Fourier transform infrared (FT-IR) spectroscopy analysis demonstrated the interactions between biopolymer blend and $\mathrm{LiBF}_{4}$. The highest value of electrical conductivity at ambient temperature $3.74 \times 10^{-6} \mathrm{~S} \mathrm{~cm}^{-1}$ was obtained for the sample containing $40 \mathrm{wt} \% \mathrm{LiBF}_{4}$. All electrolyte samples were found to obey the Arrhenius rule. The magnitude of activation energy decreases with increasing electrical conductivity and vice-versa. Rice and Roth model was applied to analyze the electrical conductivity enhancement. The temperature dependence of the frequency exponent $(s)$ shows that the conduction mechanism depends on the salt concentration, the appropriate model for low concentration was found to be correlated barrier hopping $(\mathrm{CBH})$ model, while for high salt concentration samples follow the non-overlapping small polaron tunneling (NSPT) model.

Keywords: polymer electrolyte; lithium tetrafluoroborate; conductivity; FTIR; conduction mechanism

\section{FULL TEXT}

(C) 2018 The Authors. Published by ESG (www.electrochemsci.org). This article is an open access article distributed under the terms and conditions of the Creative Commons Attribution license (http://creativecommons.org/licenses/by/4.0/). 